\title{
Infectious Laryngotracheitis: A Review
}

\section{Author(s)}

Hidalgo $\mathrm{H}$

DVM, MS

College of Veterinary Sciences

University of Chile

Santa Rosa N¹1735

La Pintana, Santiago, Chile.

Casilla 2 Correo 15

La Granja, Santiago, Chile.

E-mail: hhidalgo@uchile.cl

\section{Keywords}

Biosecurity, broiler breeders, ILT virus, laryngotracheitis, laying hens, vaccines.

\section{ABSTRACT}

Infectious laryngotracheitis (ILT) herpesvirus continues to cause outbreaks of respiratory disease in chickens world-wide. Sporadic cases of ILT occur in all classes of birds, including hobby/show/game chickens, broilers, heavy breeders, and commercial laying hens. These epornitics of ILT tend to occur where there are large populations of naïve, unvaccinated birds, i.e., in concentrated areas of broiler production. ILT virus can be transmitted through (a) chickens with acute upper respiratory tract disease, (b) latently infected "carrier" fowls, and (c) fomites and contaminated persons. Chicken flocks which are endemic infected with ILT virus occur only in some regions of countries or even in particular multiple-age production farms. In these cases modified live vaccines are actually used, even though these biological products, as well as wild ILTV strains, can establish latent infections. In the case of heavy breeders and laying hens, which are typically vaccinated against ILT, sporadic cases are often related to errors in vaccine application and to biosecurity failures.

\section{INTRODUCTION}

Infectious Laryngotracheitis (ILT) is a viral respiratory tract infection of chicken which produces severe production losses due to mortality of infected broilers, pullets and adult birds and/or decreased weight gain and egg production. Severe epizootic forms of ILT show a great respiratory distress, gasping, expectoration of bloody mucus, and high mortality. Mild forms of infection, sometimes enzootic, are characterized by mucoid tracheitis, sinusitis, unthriftiness, and low mortality.

The ILT was first described in 1925 (May \& Thittsler), and it has been described in many countries in which remains as a serious disease mainly in areas of intensive production and large concentrations of chicken such as North America, South America, Europe, China, Southeast Asia and Australia. Chicken flocks which are endemic infected with ILT virus occur only in some regions of countries or even in particular multiple-age production sites (industrial or backyard flocks). However, serious disease outbreaks continue to occur periodically whenever ILT virus strains can move from persistently infected flocks to non-vaccinated birds. In these cases modified live vaccines must to be used, even though these biological products, (as wild ILTV strains also do it), can establish latent infections The chicken is the primary natural host of ILT virus.

\section{Etiological agent}

Classification. Infectious Laryngotracheitis virus (ILTV) is classified as a member of the family Herpesviridae in the subfamily Alphaherpesvirinae. The virus is taxonomically identified as Gallid herpesvirus 1 (Roizman, 1982). 
Morphology and chemical composition. Electron micrographs of ILTV-infected chicken embryo cell cultures demonstrate the presence of icosahedral viral particles similar in morphology to herpes simplex virus. Watrach et. al. (1963) described de hexagonal nucleocapsid of ILTV to be $80-100 \mathrm{~nm}$ in diameter. The nucleocapsid have icosahedral symmetry and are composed of 162 elongated hollow capsomeres (Cruickshank et. al., 1963; Watrach et. al., 1963). The complete virus particle including an irregular envelope surrounding the nucleocapsid has a diameter of 195$250 \mathrm{~nm}$. The envelope contains fine projections representing viral glycoprotein spikes on its surface.

The nucleic acid of ILTV is comprised of DNA having a buoyant density of $1.704 \mathrm{~g} / \mathrm{mL}$, similar to other herpesviruses (Plummer et. al., 1969). Laryngotracheitis virus DNA has been reported to have a guanine plus cytosine ratio of $45 \%$ (Plummer et. al., 1969). The DNA genome consist of a linear 155-kb double-stranded molecule comprised of unique long and short segments flanked by inverted repeats (Johnson et. al., 1991; Lieb et. al., 1987). The glycoproteins of the virus, like other herpesviruses, are responsible for stimulating humoral and cell-mediated inmune responses. Five major envelope glycoproteins with molecular weights of 205, $160,115,90$, and $60 \mathrm{kD}$ have been reported (York et. al 1987; 1990). They are the major immunogens of ILT virus. LTV glycoproteins $\mathrm{gB}, \mathrm{gC}, \mathrm{gD}, \mathrm{gX}, \mathrm{gK}$ and the unique gp60 have been sequenced (Bagust \& Johnson, 1995).

Viral replication. The virus initiates infection by attachment to cell receptors followed by fusion of the envelope with the host cell plasma membrane. The nucleocapsid is released into the cytoplasm and transported to the nuclear membrane; viral DNA is released from the nucleocapsid and migrates into the nucleus through nuclear pores. Transcription and replication of viral DNA occur within the nucleus (Prideaux et. al., 1992; Guo et. al., 1993)

Transcription of ILTV DNA occurs in a highly regulated, sequentially ordered cascade similar to that of other alphaherpesviruses (Prideaux et. al., 1992). Approximately 70 virus-coded proteins are produced; several are enzymes and DNA-binding proteins that regulate viral DNA replication, but most are viral structural proteins. Viral DNA replication occurs by a rolling circle mechanism with the formation of concatemers which are cleaved into monomeric units and packaged into preformed nucleocapsids within the nucleus. DNA-filled nucleocapsids acquire an envelope by migration through the inner lamellae of the nuclear membrane. Enveloped particles then migrate through the endoplasmic reticulum and accumulate within vacuoles in the cytoplasm (Guo et. al., 1993). Enveloped virions are released by cell lysis or by vacuolar membrane fusion and exocytosis.

\section{Chemical and physical viral resistance.} Enveloped LTV infectivity is affected by organic solvents (lipolytic agents) such as chloroform and ether (Fitzgerald \& Hanson, 1963; Meulemans \& Halen, 1978a). ILT virus infectivity survives for several months when stored at $4^{\circ} \mathrm{C}$ in diluents like glycerol or nutrient broth. LTV infectivity has been rapidly inactivated by heat when exposed to $55^{\circ} \mathrm{C}$ for 15 minutes or $38^{\circ} \mathrm{C}$ for 48 hrs (Jordan, 1966). By the other hand, Meulemans \& Halen (1978b) found that $1 \%$ of the infectivity of a Belgian strain was retained after $1 \mathrm{hr}$ at $56^{\circ} \mathrm{C}$. Cover \& Benton (1958) reported that LTV is destroyed in $44 \mathrm{hrs}$ at $37^{\circ} \mathrm{C}$ in tracheal tissues within chicken carcasses or in chorioallantoic membranes (CAMs) after $5 \mathrm{hr}$ at $25^{\circ} \mathrm{C}$. However, there are earlier studies (Jordan, 1966) mentioning that LTV is able to survive in tracheal exudates and chicken carcasses for periods of 10-100 days at ambient temperatures of $13-23^{\circ} \mathrm{C}$.

LTV has been inactivated in less than 1 minute under a $3 \%$ cresol or $1 \%$ solution action. Laboratory bench surfaces can be readily decontaminated with commercial iodophors or halogen-detergent mixtures. The complete inactivation of ILTV infectivity was obtained with a 5\% hydrogen peroxide mist as a fumigant for poultry house equipment (Neighbour et al., 1994).

\section{Antigenicity and virulence of LTV strains}

ILTV strains vary in virulence for chickens (Cover \& Benton, 1958; Jordan, 1966; Pulsford, 1963; Pulsford \& Stokes, 1953), virulence for chicken embryos (Izuchi \& Hasagawa, 1982), plaque size and morphology in cell culture (Russell \& Turner, 1983), and plaque size and morphology on CAMs of embryonated chicken eggs (ECE) (Pulsford \& Stokes, 1953). Naturally occurring LTV strains vary in virulence from highly virulent strains that produce high morbidity and mortality in exposed chickens to strains of low virulence that produce mildto-inapparent infections (Cover \& Benton, 1958; Jordan, 1966; Pulsford, 1963; Pulsford \& Stokes, 1953). Laryngotracheitis virus strains appear to be antigenically homogenous based on virus-neutralization, inmunofluorescence tests, and cross-protection studies (Cover \& Benton, 1958; Shibley et. al. 1962). However, 
minor antigenic variation among strains has been suggested by the finding that some strains are neutralized poorly by heterologous antisera (Pulsford \& Stokes, 1953; Russell \& Turner, 1983; Shibley et. al. 1962).

Differentiation of ILTV strains of varying virulence, particulary wild-type and modified live-vaccine viruses, is an important practical problem. Several methods for differentiating ILTV viruses have been studied including analysis of virulence for chicken embryos (Izuchi \& Hasagawa, 1982), restriction endonuclease analyses of viral DNA (Guy et al., 1989; Kotiw et al., 1982; Lieb et al., 1987), and DNA hybridization assays (Kotiw et al., 1986). Assessment of mortality patterns in embryonated chicken eggs was proposed as a biologic system for differentiating ILTV strains (Izuchi \& Hasagawa, 1982) and mortality patterns correlated closely with virulence. Restriction endonuclease cleavage of viral DNA and electrophoretic separation of DNA fragments has been shown to distinguish different ILTV strains (Kotiw et al., 1982; Lieb et al., 1987). Restriction endonuclease analysis of LTV DNA has been used extensively in epidemiologic studies of field outbreaks to differentiate wild-type and modified live-vaccine viruses (Andreasen et al., 1990; Guy et al., 1989; Keeler et al., 1993; Keller et al., 1992). Reciprocal DNA:DNA hybridization using cloned DNA fragments also has been shown to discriminate ILTV strains ( Kotiw et al., 1986).

\section{Latence of ILTV}

As is the case of other herpesviruses, ILTV establishes latent infections, which have been demonstrated by the re-isolation of virus from the seventh week after infection by repeated tracheal swabbings (Bagust, 1986), and at 2 months after infection in tracheal organ cultures (Adair et al., 1985).

Trigeminal ganglion (TRG) is the main site of latency of ILT virus. The TRG provides the main sensory innervation to the tissues of the upper respiratory tract, and then neural viral migration is strongly inferred. Extratracheal spread of LTV to trigeminal ganglia 4-7 days after tracheal exposure was detected in $40 \%$ of chickens exposed to a virulent Australian LTV strain (Bagust et al., 1986). Reactivation of latent LTV from the trigeminal ganglia 15 months after vaccination of a flock has been also reported (Kaleta et al., 1986). Williams et al. (1992), demonstrated that mature laying chicken inoculated intratracheally with a field strain of ILTV showed viral DNA by PCR in trigeminal ganglia at 31, 46 and 61 days post - inoculation. Hughes et al. (1989) reported the re-excretion of LTV virus from latently infected chicks following the stress of re-housing and the onset of reproduction.

\section{Pathogenesis}

Transmision. Chickens are infected for ILTV through the upper respiratory and ocular routes (Beaudette, 1937). Ingestion could be another way of infection but after that, exposure of nasal epithelium must occurs (Robertson \& Egerton, 1981). More frequently, transmission occurs from acutely infected birds. Transmission through contact with clinically recovered carrier birds is more difficult to occur. ILTV infections of the upper respiratory tract of susceptible chickens is followed by intense viral replication. Infectious virus usually is present in tracheal tissues and secretions for 6-8 days PI (Bagust et al., 1986; Hitchner et al., 1977; Purcell \& McFerran, 1969; Robertson \& Egerton, 1981). The virus may remain at very low levels up to 10 days p.i. (Williams et al., 1992). No clear evidence exist for a viremic phase of infections.

Clinically inapparent LTV infection of the respiratory tract is a major feature of LT persistence. Komarov \& Beaudette (1932) and Gibbs (1933) demonstrated that collecting laryngeal and tracheal swabs from recovered infected birds and then inoculating susceptible chickens, indicated a "field" carrier rate of approximately $2 \%$ up to 16 months after a disease outbreak. Other studies with tracheal organ cultures explanted from chickens experimentally infected with Australian wild-type LTV and vaccine strains have been showed latent tracheal infections for similar periods in $50 \%$ or more of infected chickens (Bagust, 1986; Turner, 1972).

Mechanical transmission can occur by use of contaminated equipment and litter (Beaudette, 1937; Dobson, 1935; Kingbury \& Jungherr, 1958).

Clinical Signs. Clinical signs generally appear 612 days following natural exposure (Kernohan, 1931; Seddon \& Hart, 1935). Experimental inoculation via the intratracheal route results in a shorter incubation period of 2-4 days (Benton et al., 1958; Jordan, 1963; Seddon \& Hart, 1935).

Characteristic clinical signs include nasal discharge and moist rales followed by coughing, gasping, sneezing, depression and conjunctivitis (Beach, 1926; Kernohan, 1931a). When severe epizootic forms of the disease occur, signs also include labored breathing and expectoration of blood-stained mucus; and upon gross examination of the trachea, severe hemorrhages and mucus plugs are characteristics (Beach, 1926; Hinshaw 
et al., 1931; Jordan, 1958; Seddon \& Hart, 1935; Guy \& Bagust, 2003).

Clinical signs associated with mild enzootic forms include unthriftiness, reduction in egg production, eye secretion, conjunctivitis, swelling of infraorbital sinuses, persistent nasal discharge, and hemorrhagic conjunctivitis.

The course of the infection varies with the severity of lesions. Generally, most chickens recover in 10-14 days, but extremes of 1-4 week have been reported (Beach, 1926; Hinshaw et al., 1931).

Gross lesions. Gross lesions are most consistently observed in the larynx and trachea, even though the conjunctiva and other respiratory tissues could be also be affected. Tissue changes in tracheal and laryngeal tissues may be mild, with only excessive amount of mucus, conjunctivitis, sinusitis, and mucoid tracheitis (Davidson et al., 1988; Linares et al., 1994), or severe, with hemorrhage and/or diphtheric changes. In severe forms, degeneration, necrosis, and hemorrhage occur in later stages. Mucoid secretions extended along the entire length of the trachea may be present. In other cases, severe hemorrhage into the tracheal lumen may result in blood clots, or blood may be mixed with mucus and necrotic tissue. Inflammation may extend down the bronchi into the lungs and air sacs.

Edema and congestion of the epithelium of the conjunctiva and infraorbital sinuses may the only gross lesion observed in mild forms of LT.

Microscopic lesions. Early microscopic changes in tracheal mucosa include the loss of goblet cell and infiltration of mucosa with inflammatory cells. As the viral infection progresses, cell enlarge, lose cilia, and become edematous. Multynucleated cells (syncytia) are formed and lymphocytes, histiocytes, and plasma cells migrate into the mucosa and submucosa after 2-3 days. Later, cell destruction and desquamation result in a mucosal surface either covered by a thin layer of basal cells or lacking any epithelial covering; blood vessels within the lamina propia may protrude into the tracheal lumen. Hemorrhage may occur in cases of severe epithelial destruction and desquamation with exposure and rupture of blood capillaries.

Intranuclear inclusion bodies are found in epithelial cells by 3 days p.i. (Purcell, 1971). Inclusion bodies generally are present only in the early stages of infection ( 1-5 days) (Guy et al., 1992; VanderKop, 1993); they disappear as infection progresses, a result of the necrosis and desquamation of epithelial cells.

\section{Immunity}

According with Jordan (1981), several types of immune responses are involved after ILTV infection. Virus-neutralization antibodies can be detected within $5-7$ days p.i., with peak at 21 days and then antibody waned to be detected to low levels over a year (Hitchner et al., 1958). York et al. (1989) founded that total specific antibody against ILTV was detected in tracheal washings from day 5 p.i., Ig A antibody appeared at day 6 p.i., but neutralizing antibody could not be detected until day 14. In ILTV vaccinated chickens there was a substantial increase in the number of Ig A- and Ig G-synthesizing cells in the trachea by day 3 p.i. with a marked increase in the numbers of IgA-positive cells at day 7 p.i. (York et al., 1989). Secretory antibodies, including $\lg A$, are important to confer resistance to infection at mucosal surfaces, such as respiratory tract (Waldman \& Ganguly, 1974). Mucosal Ig A antibody responses are also known to be elicited more efficiently by local rather systemic administration of antigen (Gerber et al., 1978).

The role of cell-mediated immune (CMI) mechanisms in recovery from herpes infections is well established (Nash et al., 1985; Zarling, 1986).

Similar mechanisms are involved in preventing reinfection of chickens with ILTV because: (a) bursectomised chickens that are unable to synthesize specific antibodies are protected from challenge following vaccination (Robertson, 1977; Fahey et al., 1983), and (b) naive chickens can be protected against infection by the transfer of histocompatible immune lymphoid cell (Fahey et al., 1984). Circumstantial evidence for the importance of CMI also comes from reports that the titers of serum antibody to ILTV do not correlate with resistance to infection (Hitchner \& Winterfield, 1960; Shibley et al., 1962; Jordan, 1981). In addition, Fahey \& York (1990) showed that the principal mediator of ILT resistance is the local cell-mediated immune response in the trachea.

Maternal antibodies to ILTV do not protect offspring against infection or interfere with vaccination (Fahey et al., 1983). ILT vaccination or field exposure of chickens older than $2 \mathrm{wk}$ of age confer them full protection against challenge by 6-8 days (Benton et al., 1958; Gelenczei \& Marty, 1964; Hitchner, 1975). The susceptibility of chickens to ILTV declined with age and meat-type males are more susceptible than meattype females. It has been also demonstrated that high environmental temperatures (35 C) cause higher 
mortality from LTV infection in heavy adult breeds than in light adult breeds (Fahey et al., 1983).

\section{Epidemiology}

ILT is a major viral respiratory disease included within List $\mathrm{E}$ of the Office International des Epizooties (OIE). The chicken is the only significant primary host species for ILTV, and no other reservoir species have been recognized, even though pheasants and peafowls can sometimes be naturally infected by contact with chickens actively shedding ILTV (Guy \& Bagust, 2003).

The sources of ILTV are: (a) clinically affected chickens, (b) chickens which are latent carriers of infection, and (c) fomites and poultry farm personnel contaminated with ILTV.

No matter the portals of entry for ILTV (nasal, oral, conjunctiva, or even experimentally intraorbital sinus) the epithelium of the trachea and larynx is always affected by ILTV, and the most active viral replication will occur within the trachea.

In its acute form, ILT is characterized by signs of respiratory distress in birds, accompanied by gasping and expectoration of bloody exudates (Guy \& Bagust, 2003). In addition, the mucous membranes of the trachea become swollen and hemorrhagic. These events last for approximately 7 to 10 days with large amount of ILTV production. This is most important period for virus shedding.

The epizootic form of the disease spreads rapidly and although severe forms of the disease cause high morbidity (90 - 100\%), and mortality varies from $5 \%$ to $70 \%$ and averages 10-20\% (Hinshaw et al., 1931; Seddon \& Hart, 1935). Severe epizootic forms of LT were commonly described in earlier years. However, it is also possible to found mild enzootic forms of ILT observed in the intensive poultry producing areas of Europe, Australia, New Zealand and the United States (Cover \& Benton, 1958; Linares e. al., 1994; Pulsford \& Stokes, 1953; Seddon \& Hart, 1935; Webster, 1959). These result in morbidity as low as $5 \%$ with very low mortality (0,1-2\%) (Raggi et al., 1961). The author has personal evidences on some outbreaks of mild enzootic forms of ILT in some countries in South America, such as Chile, Peru, Bolivia, Argentina and Brasil.

Sporadic cases occur in all classes of birds, including hobby/show/game chickens, broilers, heavy breeders, and commercial leghorns. In the case of heavy breeders and leghorns, which are typically vaccinated against ILT, sporadic cases are often related to errors in vaccine application and to biosecurity failures: commercial table egg producers may desire to avoid the expense associated with eye drop administration of ILTV vaccine, and change to mass application. This change may result in inadequate protection. Since multiple-age layer complexes are common, and inadequately-vaccinated flock may be exposed to ILTV later, when a younger, vaccinated flock is moved into the complex and sheds the backpassaged vaccine virus, resulting in disease signs in the older flock. Cases in molted flocks that were not re-vaccinated, and the use of recently vaccinated "spiking males" in a poorly vaccinated, older breeder flock are other classic examples.

Virus shed after the latent period is another source of virus capable of causing disease in susceptible birds.

Fortunately, ILT is a slowly spreading, controllable disease. If a diagnosis of ILT is obtained early in an outbreak, vaccination of unaffected birds may induce adequate protection before they become exposed.

Administration of modified live-ILT vaccines in drinking water or by spray are desirable methods for rapid, mass application of these vaccines; however, the administration of ILT vaccines by the drinking water routes results in a high proportion of chickens that fail to develop protective immunity (Robertson \& Egerton, 1981). Application of ILT vaccines by spray may result in adverse reactions as a result of insufficient attenuation of vaccine virus, deep penetration of respiratory tract due to small droplets size of spray (Purcell \& Surman,1974), or excessive dose (Clarke et al., 1980).

Laryngotracheitis vaccine viruses have been shown to spread readily from vaccinated to nonvaccinated chickens (Andreasen et al., 1989; Churchill, 1965; Hilbink et al., 1987; Samberg et al., 1971). Such spread should be avoided, as spread to nonvaccinates results in vivo passage and possible reversion of vaccine virus to virulence (Guy et al., 1991) , or it may result in disease in unvaccinated chickens due to insufficient attenuation of vaccine virus. Since vaccination can result in latently infected carrier birds, it is recommended for use only in geographic areas where the disease in endemic. The appropriate regulatory agency should be contacted to determine approved vaccines and vaccine application procedures.

\section{Diagnosis of ILT}

ILT infections must be differentiated from others respiratory diseases which present similar clinical signs and lesions. In these cases LT diagnosis must be assisted by laboratory methods. 
ILTV isolation. Laryngotracheitis virus may be propagated in embryonated chicken eggs (ECE) and a variety of avian cell cultures. In embryonated chicken eggs the virus causes formation of opaque plaques on the CAM resulting from necrosis and proliferative tissue reactions. Plaques are observed as early as 2 days p.i. and embryo deaths occur 2-12 days later. Survival time of inoculated embryos decreases with additional egg passages (Brandly, 1937; Burnet, 1934). LTV has been propagated in a variety of avian cell cultures (CC) including chicken embryo liver (CEL), chicken embryo lung, chicken embryo kidney (CEK), and chicken kidney (CK) cell cultures (Chang et al. 1960/1977?; Hughes \& Jones, 1988; Meulemans \& Halen, 1978a; McNulty et al., 1985). Hughes \& Jones (1988) demonstrated that CEL and CK cells were more efficient for LTV isolation and propagation, with CEK cells, chicken embryo lung cells, and CAM inoculation of embryonated chicken eggs being less sensitive.Viral cytopathic effects may be observed in cell culture as early as 4-6 hr p.i. with a high multiplicity of infection. It could be found increased refractiveness and swelling of cells, chromatin displacement, and rounding of the nucleoli. Cytoplasmic fusion results in formation of multinucleated giant cells. Intranuclear inclusion bodies can be detected as early as $12 \mathrm{hr}$ post-infection. Large cytoplasmic vesicles develop in the multinucleated cells and become more basophilic as cells degenerate (Reynolds et al., 1968).

LTV has been also replicated in avian leukocyte cultures derived from chicken buffy coat (Chang et al., 1977). Calnek et al. (1986) determined that macrophage cultures were as susceptible to LTV infection as CK cells, but replication of most LTV strains examined was restricted. Both cell genotype and virus genotype influenced the extent of restriction of virus replication.

Histopathology examination remains the standard method for the rapid diagnosis of ILT. Characteristic lesions of ILT include syncytial cell formation of the tracheal epithelial cells with the development of pathognomonic intranuclear inclusion bodies, necrosis, and hemorrhage (Cover \& Benton, 1958) (Pirozok et al, 1957). Inclusion bodies are usually present in the early stages of infection, 1 to 5 days p.i., and disappear as infection progresses as a result of necrosis and desquamation of epithelial cells (Guy \& Bagust, 2003).

Diagnosis of ILT based on demonstration of inclusion bodies in tissues has been shown to be considerably less sensitive than virus isolation. Keller \& Hebel (1962) showed that inclusion bodies could be detected in 57\% of 60 specimens, while virus was isolated from $72 \%$ of the same specimens.

ILTV identification by immunoprobes. Other rapid assays for identification of ILTV utilize immunoprobes to detect viral antigens.

Fluorescent-labeled polyclonal antibodies are commonly used as immunoprobes to detect ILTV in tracheal and conjunctival smears (Braune \& Gentry, 1965; Goodwin et al., 1991; Ide, 1978; Wilks \& Kogan, 1979).

Immunoperoxidase-labeled monoclonal antibodies have been used to detect viral antigens from frozen tissue sections (Guy et al., 1992).

Monoclonal antibodies have also been used to detect viral antigens in suspensions of tracheal scraping by enzyme-linked immunosorbent assay (ELISA) (York \& Fahey, 1988)???

ILTV DNA detection. Keam et al. (1991) and Key et al., (1994) described techniques for detection of LTV DNA utilizing dot-blot hybridization assay and cloned LTV DNA fragments labeled with digoxigenin. These procedures were shown to be highly sensitive for detection of LTV in acutely infected chickens, as well as convalescent chickens, when detection was no longer possible using virus isolation and ELISA. These assays also were shown to provide rapid methods for detection of chickens latently infected with LTV. Polymerase chain reaction (PCR) tests for detection of LTV DNA have been described by Shirley et al.(1990) and Williams et al. (1994).

Electron microscopic examination. Rapid diagnosis of LT also has been accomplished using direct electron microscopic examination of tracheal scrapings (Hughes \& Jones, 1988; Van Kammen \& Spradbrow, 1976). Diagnosis is dependent upon visualization and morphologic identification of herpesviruses and, thus, is successful only when large numbers of virus particles are present in clinical samples. Hughes \& Jones (1988) found that virus particles were observed only when clinical samples contained a minimum titer of $3.5 \log 10$ of infectious virus.

Serology. Demonstration of LTV antibodies in serum can be done through different tests: agar gel immunodiffusion (AGID), virus neutralization (VN) in ECE or CC, indirect fluorescent antibody (IFA) test, and ELISA. Actually, ELISA offers ease of testing for large number 
of sera. This method has been demonstrated to be more sensitive than VN (Adair et al., 1985; Bauer et al., 1999), and of comparable sensitivity of IFA, with AGID being the least sensitive (Adair et al., 1985).

\section{Management procedures for prevention and control}

For intensive broiler production, the short growth cycle and high level of biosecurity measures on farms can reduce the need for prophylactic vaccination.

The application of biosecurity measures will avoid exposing susceptible chickens via contaminated fomites. The importance of site quarantine and hygiene in preventing the movement of potentially contaminated personnel, feed, equipment, and birds is central to successful prevention and control of ILT (Kingsbury \& Jungherr, 1958).

Cooperative control of ILT outbreaks by collaboration between government and industry is most desirable. Where outbreaks have been contained, recovered flocks should be moved for processing under quarantine as soon as possible. Experience with ILT outbreaks in Pennsylvania (Davidson \& Miller, 1988) indicates that this interval can be as short as $2 \mathrm{wk}$ after the last clinical signs of $\mathrm{LT}$ are observed on a farm.

For control of an ILT outbreak, the most effective approach is a coordinated effort to obtain a rapid diagnosis, to establish a vaccination program, and prevent further virus spread. Vaccination in the face of an outbreak will both limit virus spread and shorten duration of the disease. Spread of LTV between farms can be prevented by appropriated biosecurity measures. Laryngotracheitis virus infectivity is readily inactivated outside the host chicken by disinfectants and warm temperatures, thus carryover between successive flocks in a house can be prevented by adequate cleanup.

\section{Immunization for prevention and control}

ILTV infections are usually limited to the upper respiratory tract and viremia is rarely observed. Furthermore, the humoral immune response, including secretory and maternal antibodies, and levels of neutralizing antibodies do not correlate well with protection. Instead, protection seems to be mediated primarily by the cellular immune response. These points are important to consider in the development of a vaccination strategy. Any effective vaccine will have to elicit an effective mucosal, cell-mediated, protective immune response.
Vaccination for ILT has generally been used only in areas where the disease is endemic, since vaccination can result in the occurrence of long-term "carrier" birds due to the virus' ability to enter a latent state in the sensory ganglia. Furthermore, current vaccines are themselves mildly pathogenic, with a resulting economic "cost". There is justifiable concern over the negative performance (growth, mortality, feed conversion) associated with current ILT vaccines. Guy et al. (1991) have reported that modified live ILT vaccines increase in virulence by mutation during bird-to-bird passage in the field. This has led to an additional reluctance to vaccinate for ILT unless a region is faced with an active outbreak of the disease. Other groups contend that vaccine strains of ILTV are genetically stable (Keeler et al., 1993). However, by spreading into flocks that may contain birds of different ages and with a different immune status, the incompletely attenuated modified live vaccine strains of ILTV may manifest a clinically more severe disease.

Traditional live attenuated ILT vaccines. Traditionally there have been two sources of live attenuated ILT vaccines. Vaccines attenuated by multiple passages in embryonating eggs (CEO) (Samberg et al., 1971), are higher effective. However, in many cases their use can result in lower performance and higher condemnation rates. Broilers are generally vaccinated with CEO vaccine by drinking water only in the face of an outbreak. Furthermore, CEO-derived vaccine strains of ILTV are generally indistinguishable from true field isolates of ILTV (Guy et al., 1990), providing diagnosticians and regulators with additional challenges. ILT vaccines generated by multiple passages in tissue culture (TCO) (Gelenczei \& Marty, 1964) generally offer less protection as they are more highly attenuated and less immunogenic. TCO vaccines are commonly used in layer breeders and layers.

Live attenuated ILT vaccines provide immunity when apply via infraorbital sinuses (Shibley et al. 1962), intranasal instillation (Benton et al., 1958), eye drop (Sinkovic \& Hunt, 1968), and orally through drinking water (Samberg et al., 1971). However, application of ILT vaccines by eye drop method appears to be more protective than application by water or spray (Fulton et al., 2000). Most vaccines when given by eye drop method had lower mean microscopic lesion scores and higher ELISA titers after one vaccination. In contrast to other mass application methods, eye drop vaccination in flock situations when applied correctly ensures that all birds in that flock have received vaccine. Careful 
attention must be given to procedures of vaccine administration to ensure adequate immunization.

Recombinant subunit vaccines. There are many reported experiments on the use of Fowlpox virus and Marek's disease virus as vectors for the insertion of genes from avian pathogens. In these cases, a gene encoding an immunogenic protein is inserted into a region of the host genome which is nonessential for the host's replication. ILTV genes have also been inserted into these vectors, and these efforts have involved either the ILTV glycoprotein B or glycoprotein D genes (Keeler et al., 1992). In both cases these are virally-encoded structural glycoproteins which are located on the viral envelope and the surface of infected cells and are required for viral attachment. The ILTV genes for these two proteins have been inserted into fowlpox or Marek's disease virus vector systems. The recombinant viruses produce proteins, which are immunogenic and elicit a protective immune response. At the moment, a vaccine on the base of a live Fowl Poxvirus vector genetically modified to express key protective ILTV antigens has been licensed and it is commercially available.

Live attenuated recombinant ILT vaccines. Recombinant vaccines for the poultry industry have been constructed by selecting for relatively rare in vivo homologous recombination events. This technique depends on introducing a DNA fragment into tissue culture cells by transfection and then co-transfecting the culture with viral DNA or infecting the culture with virus. This technique can be used to mutate a viral gene by replacing it with a foreign, or marker, gene. It has been successfully constructed defined ILTV mutants for thymidine kinase gene (Guo et al., 1994; Okamura et al., 1994; Schnitzlein et al., 1995). The protein encoded by this gene is involved in DNA metabolism and viral pathogenicity. For different reasons these initial live attenuated strains of ILTV have not been suitable commercial vaccine candidates.

Novel vaccines approaches. Genetic immunization is another approach to induce protective immunity to infectious diseases. DNA vaccines can be relatively quick and easy to generate. Plasmid DNA is not infectious and it doesn't replicate. Furthermore, plasmid DNA is stable and can be stored under conditions that would destroy a live virus. In addition, plasmid DNA can be administered by a variety of methods, including the potential of in ovo administration. The first ILTV DNA vaccination experiments were reported in 1995 (Keeler et al., 1995). Birds vaccinated intramuscularly with DNA encoding glycoprotein B were found to have levels of protection comparable to those vaccinated with traditional live attenuated ILTV vaccines. Enhancement of DNA vaccine efficacy and the development of a practical cost-effective application of this technology will be required before its acceptance by the poultry industry.

\section{Eradication}

Eradication of LTV from intensive poultry production sites appears to be highly feasible due to several biologic and ecologic properties of the virus. These properties include the high degree of host-specificity of the virus, the relative fragility of ILTV infectivity outside the chicken, and antigenic stability of ILTV genome (Bagust \& Johnson,1995). Furthermore, the chicken is the primary host species as well as the reservoir host. Because ILTV strains are antigenically homogeneous a single LTV vaccine produces cross-protective immunity for all LTV strains.

Considering that backyard and fancier chicken flocks are likely reservoirs of LTV, they must be included in any eradication effort (Mallinson et al.,1981).

Eradication of LTV will be facilitated in the future The development of ILT genetically engineered vaccines, that induce protective immunity without induction of latently infected carrier chickens, it will be easier to initiate eradication programs (Bagust \& Johnson, 1995). Actually, a vaccine on the base of a live Fowl Poxvirus vector genetically modified to express key protective ILTV antigens is commercially available

\section{References}

Adair BM, Todd D, McKillop ER, Burns K. Comparison of serological tests for detection of antibodies to infectious laryngotracheitis virus. Avian Pathology 1985; 14:461-469.

Andreasen JR. Jr, Glisson JR, Goodwin MA, Resurreccion RS, Villegas $P$, Brown J. Studies of infectious laryngotracheitis vaccines: Immunity in layers. Avian Diseases 1989; 33:524-530.

Andreasen JR, Glisson JR, Villegas P. Differentiation of vaccine strains and Georgia field isolates of infectious laryngotracheitis virus by their restriction endonuclease fragment patterns. Avian Diseases 1990; 34:646-656.

Bagust TJ. Laryngotracheitis (Gallid-1) herpesvirus infection in the chicken. 4 Latency establishment by wild and vaccine strains of ILT virus. Avian Pathology 1986; 15:581-595.

Bagust TJ, Johnson MA. Avian infectious laryngotracheitis: Virus- 
host interactions in relation to prospects for eradication. Avian Pathology 1995; 24:373-391.

Bagust TJ, Calnek BW, Fahey KJ. Gallid-1 herpesvirus infection in the chicken. 3. Reinvestigation of the pathogenesis of infectious laryngotracheitis in acute and early post-acute respiratory disease. Avian Diseases 1986; 30:179-190.

Bauer B, Lohr JE, Kaleta EF. Comparison of commercial ELISA kits from Australia and the USA with the serum neutralisation test in cell cultures for the detection of antibodies to the infectious laryngotracheitis virus of chickens. Avian Pathology 1999; 28:6572.

Beach, JR. Infectious bronchitis of fowls. Journal of American Veterinary Medical Association 1926; 68:570-580.

Beaudette FR. Infectious laryngotracheitis. Poultry. Science 1937; 16:103-105.

Benton WJ, Cover MS, Greene LM. The clinical and serological response of chickens to certain laryngotracheitis viruses. Avian Diseases 1958; 2:383-396.

Brandly CA. Studies on certain filterable viruses. I. Factors concerned with the egg propagation of fowl pox and infectious laryngotracheitis. Journal American Veterinary Medical Association 1937; 90:479-487.

Braune MO, Gentry RF.Standardization of the fluorescent antibody technique for the detection of avian respiratory viruses. Avian Diseases 1965; 9:535-545.

Burnet $F$. The propagation of the virus of infectious laryngotracheitis on the CAM of the developing egg. British Journal of Experimental Pathology 1934; 15:52-55.

Calnek BW, Fahey KJ, Bagust TJ. In vitro infection studies with infectious laryngotracheitis virus. Avian Diseases 1986; 30:327-336.

Chang PW, Sculo F, Yates VJ. An in vivo and in vitro study of infectious laryngotracheitis virus in chicken leukocytes. Avian Diseases 1977; 21:492-500.

Churchill AE. The development of a live attenuated infectious laryngotracheitis vaccine. Veterinary Record 1965a; 77:1227-1234.

Churchill AE. The use of chicken kidney tissue cultures in the study of the avian viruses of Newcastle disease, infectious laryngotracheitis, and infectious bronchitis. Research Veterinary Science 1965b; 6:162-169.

Clarke JK, Robertson GM, Purcell DA. Spray vaccination of chickens using infectious laryngotracheitis virus. Australian Veterinary Journal 1980; 56:424-428.

Cover MS, Benton WJ. The biological variation of infectious laryngotracheitis virus. Avian Diseases 1958; 2:375-383.

Cruickshank JG, Berry DM, Hay B. The fine structure of infectious laryngotracheitis virus. Virology 1963; 20:376-378.
Davidson S, Miller K. Recent laryngotracheitis outbreaks in Pennsylvania. Proceeding. $37^{\text {th }}$ West Poultry Conference, Sacramento, CA. 1988. pp. 135-136.

Davidson S, Eckroade R, Miller K. Laryngotracheitis the Pennsylvania experience. Proceeding $23^{\text {rd }}$ National Meet and Poultry Health Condemnations. Ocean City, MD.1988. pp. 14-19.

Dobson N. Infectious laryngotracheitis in poultry. Veterinary Record 1935; 15:1467-1471.

Fahey KJ, Bagust TJ, York JJ. Laryngotracheitis herpesvirus infection in the chicken:The role of humoral antibody in immunity to a graded challenge infection. Avian Pathology 1983; 12:505-514.

Fahey KJ, York JJ, Bagust TJ. Laryngotracheitis herpesvirus infection in the chicken. 2. The adoptive transfer of resistance to a graded challenge infection. Avian Pathology 1984; 13:265-275.

Fahey KJ, York JJ. The role of mucosal antibody in immunity to infectious laryngotracheitis virus in chickens. Journal of General Virology 1990; 71:2401-2405.

Fitzgerald JE, Hanson LE. A comparison of some properties of laryngotracheitis and herpes simplex viruses. American Journal of Veterinary Research 1963; 24:1297-1303.

Fulton RM, Schrader DL, Will M. Effect of route of vaccination on the prevention of infectious laryngotracheitis in commercial egglaying chickens. Avian Diseases 2000; 44:8-16.

Gelencezei EF, Marty EW. Studies on a tissue-culture modified infectious laryngotracheitis virus. Avian Diseases 1964; 8:105-122.

Gerber JD, Marron AE, Kucera CJ. Local and systemic cellular and antibody immune responses of cattle to infectious bovine rhinotracheitis virus vaccine administered intranasally or intramuscularly. American Journal of Veterinary Research 1978; 39:753-760.

Gibbs CS.The Massachusetts plan for the eradication and control of infectious laryngotracheitis. Journal of American Veterinary Medical Association 1933; 83:214-217.

Goodwin MA, Smeltzer MA, Brown J, Resurreccion RS, Dickson TG. Comparison of histopathology to the direct immunofluorescent antibody test for the diagnosis of infectious laryngotracheitis in chickens. Avian Diseases 1991; 35:389-391.

Guo P, Scholz E, Turek J, Nordgreen R, Maloney B. 1993. Assembly pathway of avian infectious laryngotracheitis virus. American Journal of Veterinary Research. 54:2031-2039.

Guo P, Scholz E, Maloney B, Welniak E. Construction of recombinant avian infectious laryngotracheitis virus expressing the $\beta$-galactosidase gene and DNA sequencing of the insertion region. Virology 1994; 202:771-781.

Guy JS, Bagust TJ. Laringotracheitis. In Diseases of poultry, $11^{\text {th }}$ Ed. (Y.M. Saif with H.J. Barnes, A.M. Fadly, J.R.Glisson, L.R. McDougald and D.E. Swayne, eds). lowa State University Press, Ames.2003. pp. 121-134. 
Guy JS, Barnes HJ, Munger LL, Rose L. Restriction endonuclease analysis of infectious laryngotracheitis viruses:Comparison of modified-live vaccine viruses and North Carolina field isolates. Avian Diseases 1989; 33:316-323.

Guy JS, Barnes HJ, Morgan LM. 1990. Virulence of infectious laryngotracheitis viruses: Comparison of modified-live vaccine viruses and North Carolina field isolates. Avian Diseases. 34:106-113.

Guy JS, Barnes HJ, Smith LG. Increased virulence of modified-live infectious laryngotracheitis vaccine virus following bird-to-bird passage. Avian Diseases 1991; 35:348-355.

Guy JS, Barnes HJ, Smith LG. Rapid diagnosis of infectious laryngotracheitis using a monoclonal antibody-based immunoperoxidase procedure. Avian Pathology 1992; 21:77-86.

Hilbink FW, Oei HL, Van Roozelaar DJ.Virulence of five live virus vaccines against infectious laryngotracheitis and their immunogenicity and spread after eyedrop or spray application. The Veterinary Quarterly 1987; 9:215-225.

Hinshaw WR, Jones EC, Graybill HW. A study of mortality and egg production in flocks affected with laryngotracheitis. Poultry Science $1931 ; 10: 375-382$.

Hitchner SB, Shea CA, White PG. Studies on a serum neutralization test for diagnosis of laryngotracheitis in chickens. Avian Diseases 1958; 2:258-269.

Hitchner SB. Infectious laryngotracheitis:The virus and the immune response. American Journal Veterinary Research 1975; 36:518519.

Hitchner SB, Winterfield RW. Revaccination procedures for infectious laryngotracheitis. Avian Diseases 1960; 4:291-303.

Hitchner SB, Fabricant J, Bagust TJ. A fluorescent-antibody study of the pathogenesis of infectious laryngotracheitis. Avian Diseases 1977; 21:185-194.

Hughes CS, Jones RC. Comparison of cultural methods for primary isolation of infectious laryngotracheitis virus from field materials. Avian Pathology 1988; 17:295-303.

Hughes CS, Gaskell RM, Jones RC, Bradbury JM, Jordan FTW. Effects of certain stress factors on the re-excretion of infectious laryngotracheitis virus from latently infected carrier birds. Research in Veterinary Sciences 1989; 46:247-276.

Ide PR. Sensitivity and specificity of the fluorescent antibody technique for detection of infectious laryngotracheitis virus. Canadian Journal of Comparative Medicine 1978; 42:54-62.

Izuchi T, Hasagawa A.Pathogenicity of infectious laryngotracheitis virus as measured by chicken embryo inoculation. Avian Diseases $1982 ; 26: 18-25$.

Johnson MA, Prideaux CT, Kongsuwan K, Sheppard M, Fahey KJ. Gallid herpesvirus I (infectious laryngotracheitis virus):Cloning and physical maps of the SA-2 strain. Archives of Virology 1991; 119:181-198.
Jordan, FTW. Some observations of infectious laryngotracheitis. Veterinary Record 1958; 70:605-610.

Jordan, FTW. 1963. Further observations of the epidemiology of infectious laryngotracheitis of poultry. Journal of Comparative Pathology. 73:253-264

Jordan, FTW. A review of the literature on infectious laryngotracheitis. Avian Diseases 1966; 10:1-26.

Jordan, FTW. Immunity to infectious laryngotracheitis. In M.E. Ross, J. N. Payne and B.M. Freeman (eds). Avian Immunology. British Poultry Science Ltd., Edinburgh, Scotland. 1981. pp. 245-254.

Kaleta EF, Redman TH, Heffeis-Redman U, Frese K.Zum Nachweis der Latenz des attenuierten virus der infektiosen laryngotracheitis des Huhnes im trigeminusganglion, Dtsch Tieraerztl Wochenschr 1986; 93:40-42.

Keam L, York JJ, Sheppard M, Fahey KJ.Detection of infectious laryngotracheitis virus in chickens using a non-radioactive DNA probe. Avian Diseases 1991; 35:257-262.

Keeler CL, Hazel JW, Hastings JE, Rosenberger JK. Restriction endonuclease analysis of Delmarva field isolates of infectious laryngotracheitis virus. Avian Diseases 1993; 37:418-426.

Keeler C Jr, Poulsen D, Robinson H, Santoro J, Thureen D. Immunization of chickens with gene (DNA) vaccines. $132^{\text {nd }}$ Annual Meeting of the AVMA. Pittsburgh, PA. 1995. p143.

Keller K, Hebel P.Diagnostico de las inclusiones de laringotraqueitis infecciosa en frotis y cortes histológicos. Zooiatria (Chile) 1962;1:1.

Keller LH, Benson CE, Davison S, Eckroade RJ. Differences among restriction endonuclease DNA fingerprints of Pennsylvania field isolates, vaccines strais and challenge strains of infectious laryngotracheitis virus. Avian Diseases 1992; 36:575-581.

Kernohan G. Infectious laryngotracheitis in fowls. Journal of American Veterinary Medical Association 1931a; 78:196-202.

Kernohan G. Infectious laryngotracheitis in pheasants. Journal of American Veterinary Medical Association 1931b; 78:553-555.

Key DW, Gough BC, Derbyshire JB, Nagy E. Development and evaluation of a non-isotopically labelled DNA probe for the diagnosis of infectious laryngotracheitis. Avian Diseases 1994; 38:467-474.

Kingsbury FW, Jungherr EL. Indirect transmission of infectious laryngotracheitis in chickens. Avian Diseases 1958; 2:54-63.

Komarov A, Beaudette FR.Carriers of infectious bronchitis. Poultry Science 1932; 11:335-338.

Kotiw M, Wilks CR, May JT. Differentiation of infectious laryngotracheitis virus strains using restriction endonucleases. Avian Diseases 1982; 26:718-731.

Kotiw M, Sheppard M, May JT, Wilks CR. Differentiation between virulen and avirulent strains of infectious laryngotracheitis virus by 
DNA:DNA hybridisation using a cloned DNA marker. Veterinary Microbiology 1986; 11:319-330.

Lieb DA, Bradbury JM, Hart CA, McCarthy K.Genome isomerism in two alphaherpesviruses:Herpes saimiri-1 (herpesvirus tamaerinus) and avian infectious laryngotracheitis virus. Archives of Virology 1987; 93:287-294.

Linares JA, Bickford AA, Cooper GL, Charlton BR, Woolcock PR. An outbreak of infectious laryngotracheitis in California broilers. Avian Diseases 1994; 38:188-192.

Mallinson ET, Miller KF, Murphy CD. Cooperative control of infectious laryngotracheitis. Avian Diseases 1981; 25:723-729.

May HG, Thittsler RP.Tracheo-laryngotracheitis in poultry. Journal of American Veterinary Medical Association 1925; 67:229-231.

McNulty MS, Allan GM, McCracken RM. Infectious laryngotracheitis in Ireland. Irish Veterinary Journal 1985; 39:124-125.

Meulemans G, Halen P. A comparison of three methods for diagnosis of infectious laryngotracheitis. Avian Pathology 1978a; 7:433-436

Meulemans G, Halen P. Some physiochemical and biological properties of a Belgian strain (U76/1035) of infectious laryngotracheitis virus. Avian Pathology 1978b; 7:311-315.

Nash AA, Leung KN, Wildy P. 1985. The T-cell mediated immune response of mice to herpes simplex virus. In:Herpesviruses. Roizman B. \& Lopez C.(eds). New York:Plenum Press. Vol. 4. 1985. p.87102.

Neighbour NK, Newberry LA, Bayyari GR, Skeeles JK, Beasley JN, McNew RW. The effect of microaerosolized hydrogen peroxide on bacterial and viral pathogens. Poultry Science 1994; 73:1511-1516.

Okamura H, Sakaguchi M, Honda T, Taneno A, Matsuo K, Yamada $S$. Construction of recombinant laryngotracheitis virus expressing the lac-Z gene of $E$. coli with thymidine kinase gene. Journal of Veterinary Medical Science 1994; 56:799-801.

Pirozok RP, Helmbolt CF, Jungherr EL. A rapid histological technique for the diagnosis of infectious avian laryngotracheitis. Journal of American Veterinary Medical Association 1957; 130:406-407.

Plummer G, Goodheart CR, Henson D, Bowling CP. A comparative study of the DNA density and behavior in tissue culture of fourteen different herpesviruses. Virology 1969; 39:134-137.

Prideaux CT, Kongsuwan K, Johnson MA, Sheppard M, Fahey KJ. Infectious laryngotracheitis virus growth, DNA replication, and protein synthesis. Archives of Virology 1992; 123:181-192.

Pulsford MF. Infectious laryngotracheitis of poultry. Part I. Virus variation, immunology and vaccination. Veterinary Bulletin 1963; 33:415-420.

Pulsford MF, Stokes J. Infectious laryngotracheitis in South Australia. Australian Veterinary Journal 1953; 29:8-12.
Purcell DA. The ultrastructural changes produced by infectious laryngotracheitis virus in tracheal epithelium of the fowl. Research of Veterinary Science 1971; 12:455-458.

Purcell DA, McFerran JB. Influence of method of infection on the pathogenesis of infectious laryngotracheitis. Journal of Comparative Pathology 1969; 79:285-291.

Purcell DA, Surman PG. Aerosol administration of the SA-2 vaccine strain of infectious laryngotracheitis virus. Australian Veterinary Journal 1974; 50:419-420.

Raggi LG, Brownell JR, Stewart GF. Effect of infectious laryngotracheitis on egg production and quality. Poultry. Science $1961 ; 40: 134-140$.

Reynolds HA, Watrach AW, Hanson LE. Development of the nuclear inclusion bodies of infectious laryngotracheitis. Avian Diseases 1968; $12: 332-347$

Robertson GM. The role of bursa-dependent responses in immunity to infectious laryngotracheitis. Reserch of Veterinary Science 1977; 22:281-284.

Robertson GM, Egerton JR. Micro-assay systems for infectious laryngotracheitis virus. Avian Diseases 1977; 21:133-135.

Robertson GM, Egerton JR. Replication of infectious laryngotracheitis virus in chickens following vaccination. Australian Veterinary Journal 1981; 57:119-123.

Roizman B.The family Herpesviridae:General description, taxonomy and classification. In:B. Roizman (ed). The Herpesviruses, Vol. I. Plenum Press, New York. 1982. pp. 1-23.

Russell RG, Turner AJ. Characterization of infectious laryngotracheitis viruses, antigenic comparison of neutralization and immunization studies. Canadian Journal of Comparative Medicine 1983; 47:163-171.

Samberg Y, Cuperstein E, Bendheim U, Aronovici I. The development of a vaccine against avian infectious laryngotracheitis. IV Immunization of chickens with modified laryngotracheitis vaccine in the drinking water. Avian Diseases 1971; 15:413-417.

Schnitzlein WM, Winans R, Ellsworth S, Tripathy DN. Generation of thymidine kinase-deficient mutants of infectious laryngotracheitis virus. Virology 1995; 209:304-314.

Seddon HR, Hart L. The occurrence of infectious laryngotracheitis in fowls in New South Wales. Australian Veterinary Journal 1935; $11: 212-222$.

Shibley GP, Luginbunhl RE, Helmboldt CF. A study of infectious laryngotracheitis virus. I. Comparison of serologic and immunogenic properties. Avian Diseases 1962; 6:59-71.

Shirley MW, Kemp DJ, Sheppard M, Fahey KJ. Detection of DNA from infectious laryngotracheitis virus by colourimetric analyses of polymerase chain reactions. Journal of Virological Methods 1990; 30:251-260. 
Sinkovic B, Hunt S. Vaccination of day-old chickens against infectious laryngotracheitis by conjunctival instillation. Australian Veterinary Journal 1968; 44:55-57.

Turner AJ. Persistence of virus in respiratory infections of chickens. Australian Veterinary Journal 1972; 48:361-363.

VanderKop MA. Infectious laryngotracheitis in commercial broiler chickens. Canadian of Veterinary Journal 1993; 34:185.

Van Kammen A, Spradbrow PB. Rapid diagnosis of some avian virus diseases. Avian Diseases 1976; 20:748-751.

Waldman RH, Ganguly R. Immunity to infections on secretory surfaces. Journal of infectious Diseases 1974; 130:419-440.

Watrach AM, Hanson LE, Watrach MA. The structure of infectious laryngotracheitis virus. Virology 1963; 21:601-608

Webster RG. Studies on infectious laryngotracheitis in New Zealand. New Zealand. Veterinary Journal 1959; 7:67-71.

Wilks CR, Kogan VG. An immunofluorescence diagnostic test for avian infectious laryngotracheitis. Australian Veterinary Journal 1979; 55:385-388.

Williams RA, Bennett M, Bradbury JM, Gaskell RM, Jones RC, Jordan FTW. Demonstration of sites of latency of infectious laringotracheitis virus using the polymerase chain reaction. Journal of General Virology 1992; 73:2415-2430.

Williams RA, Savage CE, Jones RC. A comparison of direct electron microscopy, virus isolation, and a DNA amplification method for the detection of avian infectious laryngotracheitis virus in field material. Avian Pathology 1994; 23:709-720.

York JJ, Sonza S, Fahey KJ. Immunogenic glycoproteins of infectious laryngotracheitis herpesvirus. Virology 1987; 161:340-347.

York JJ, Young JG, Fahey KJ. The appearance of viral antigen and antibody in the trachea of naïve and vaccinated chickens infected with infectious laryngotracheitis virus. Avian Pathology 1989; 18:643-658

York JJ, Sonza S, Brandon MR, Fahey KJ. Antigens of infectious laryngotracheitis herpesvirus defined by monoclonal antibodies. Archives of Virology 1990; 115:147-162.

Zarling JM. 1986. T cell mediated immunity to herpes simplex viruses. In:Human Herpes-virus Infection. Lopez C. \& Roizman B. New York:Raven Press. 1986. p.103-114. 